\title{
Simulation and Modelling of Safety of Roadways in Reverse Horizontal Curves (RHCs): With Focus on Lateral Friction Coefficient
}

\author{
Maziyar Khanjari $\mathbb{D D}^{1}$ Ali Abdi Kordani $\mathbb{D}^{2},{ }^{2}$ and Saeed Monajjem $\mathbb{D}^{3}$ \\ ${ }^{1}$ MSC, Islamic Azad University, Science and Research Branch, Tehran, Iran \\ ${ }^{2}$ Faculty of Technical \& Engineering, Imam Khomeini International University, Qazvin, Iran \\ ${ }^{3}$ Faculty of Civil Engineering, K.N. Toosi University of Technology, Tehran, Iran \\ Correspondence should be addressed to Maziyar Khanjari; maziyar.khanjari@srbiau.ac.ir
}

Received 21 August 2021; Revised 1 December 2021; Accepted 27 January 2022; Published 7 March 2022

Academic Editor: Yajie Zou

Copyright (c) 2022 Maziyar Khanjari et al. This is an open access article distributed under the Creative Commons Attribution License, which permits unrestricted use, distribution, and reproduction in any medium, provided the original work is properly cited.

\begin{abstract}
Reverse Horizontal Curves (RHCs) are among the most accident-prone road points, with many annual fatalities and injuries. These fatalities can increase dramatically if the RHCs and longitudinal slopes are combined. The importance of increasing the safety of RHCs, especially in mountainous routes, is doubled due to the possibility of combining RHCs with vertical extensions or combining them with so-called steep slopes. This study used vehicle dynamic modeling to evaluate the lateral friction of various vehicles. Including the E-Class Sedan, E-Class SUV, Truck, and Bus, moving on RHCs combined with a longitudinal slope (downgrade, upgrade, and direct distance). Then, the RHC lateral friction model was presented using the multiple regression model based on the effective parameters, including design speeds, direct distance, and different longitudinal slopes. The results showed that speed, longitudinal slope, and vehicle type had the most impact, and direct distance had the most negligible impact in friction coefficient models. Based on the modeling results, the higher the design's speed and the shorter the direct distance, the lower the lateral friction coefficient for the Sedan and SUV. Hence, the safety of the vehicles is greater. For trucks, reduced speed, increased direct distance, and reduced slope led to increased safety. In the results, the most critical state was the lateral friction coefficient at a speed of $80 \mathrm{~km} / \mathrm{h}$ and a direct distance of $116 \mathrm{~m}$ for the SUV.
\end{abstract}

\section{Introduction}

The road factor, along with both human and vehicle factors, plays an influential role in road accidents. Therefore, providing proper road safety by modifying the geometric design of the road is important in reducing road accidents [1]. Horizontal curves are one of the most dangerous and accident-prone parts of the road due to the centrifugal force of the vehicles, which always attracts special attention to itself for reducing accidents [2]. The safety of these curves depends on many factors, the most important of which are the road's geometric characteristics [3-5]. The importance of increasing the safety of horizontal curves, especially in mountainous routes, is doubled due to the possibility of combining horizontal curves with vertical extension or combining them with so-called steep slopes. In addition to mountainous areas, interchanges inside or outside the city are a clear example of the combination of horizontal curves with vertical extension, which is almost inevitable [6].

Due to the possibility of combining RHCs with steep slopes, the importance of increasing the safety of Reverse Horizontal Curves (RHCs) on mountain trails is of greater importance. The American Association of State Highway and Transportation Officials (AASHTO) considers a maximum value of 1.5 for the ratio between the larger radius and the smallest reverse radius [7] and does not provide any other instructions for correcting the geometry of RHCs combined with the extension of the route. According to a project by the Transportation Research Board (TRB), the lateral friction increases on downgrades due to the braking 
force and on upgrades due to tractive force. This amount of increase in the lateral friction reduces the safety margin of the curve. Suppose this lateral friction exceeds the amount of lateral friction in the curve. In that case, it causes critical and unsafe conditions for vehicles to cross the curve $[8,9]$. Unfortunately, these changes in friction along the upgrade and downgrade routes have also been ignored in the AASHTO's instructions. Hence, this results in a lack of proper understanding and knowledge of the accident-prone areas of the route for correction and improvement.

AASHTO's horizontal curve radius equation based on the point mass model has been provided [10]. The point mass model on a curve with superelevation and fixed radius is the most straightforward vehicle model for designing horizontal curves. In this regard, the car's dynamical analysis must be considered as a body with certain dimensions and not a point mass. The result of the dynamic analysis in equilibrium conditions of the vehicle leads to a criterion in which the vehicle suspension system and its dimensions, especially the distance from the center of mass to the ground and the axial distance between the left and right wheels, is effective in balancing the vehicle. One of the basic and important limitations of the point mass model is that it ignores the difference in force distribution on the different wheels and axles of the vehicle. However, the distribution of force in vehicles varies according to the distance between the front and rear axles from the center of gravity [11]. Another limitation of the point mass model is that it does not express inverse and compound curve calculations alone or in combination with a vertical route [6].

In recent years, vehicles have improved in both terms of safety and quality with the development of automotive engineering technology and road engineering together, which are the two main parameters to increase road safety and reduceing road fatalities. Unfortunately, road designs are not compatible with modern vehicles. Therefore, one of the main drawbacks of the existing equation of the horizontal curve design is the failure in considering the vehicle parameters in the equation. Thus, this research has another advantage: the adaptation of the proposed equation between the lateral friction coefficient and the effective characteristics of vehicles to the geometric design of the routes. Therefore, contrary to AASHTO's assumption and most studies and research on the subject that have used the point mass model, in this study, the vehicle dynamic modeling method was used to study the safety of different vehicles passing through the RHC by considering the lateral friction coefficient.

\section{Literature Review}

Various researches have studied the safety effects of road geometry related to pavement conditions along with some changes in pavement surface conditions. However, more studies are needed in terms of vehicle stability and controllability (which depend on pavement surface conditions) [12]. Pavement surface friction is one of the most critical issues in traffic safety. A low coefficient of friction due to surface polishing or misalignment is a potential risk for accidents [13]. As shown in Figure 1, increasing the speed

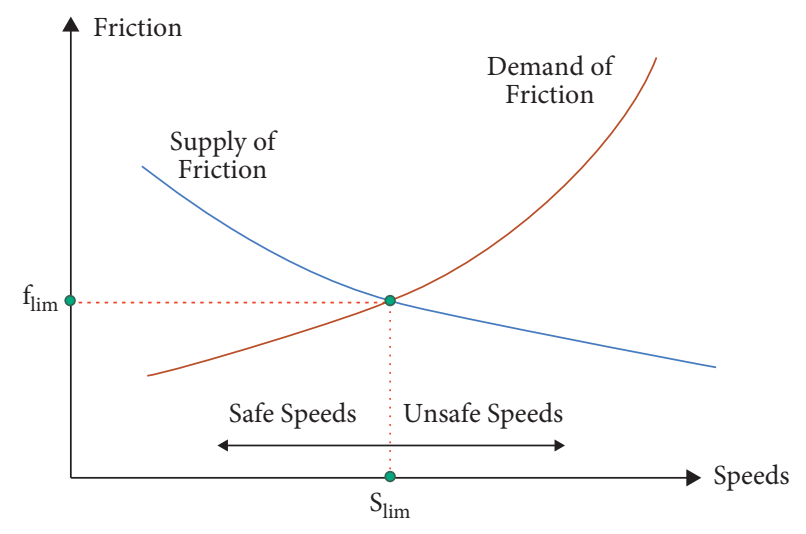

FIgURE 1: Relationship between existing friction and required friction in a circular horizontal curve [13].

and reducing the existing friction increases the necessary friction, resulting in a greater risk of accidents, especially in the curve.

Morrall and Talarico examined the required lateral friction coefficient and the safety margin on the horizontal curves. In order to estimate the curve safety margin provided to withstand slipping, lateral friction in the relative slipping condition and the required maximum lateral friction must be defined. Different safety margins were proposed for dry, wet, and frozen pavements since lateral friction in impending slipping depended on pavement surface conditions [14].

Dabbour et al. determined the required minimum radius for RHCs on freeway based on vehicle stability using vehicle dynamic model to simulate truck behavior on different alignments. The results showed that an increase in the minimum radius requirement for RHC is needed to maintain driver comfort levels and prevent potential rollover. This increase was from 8.3 to $28.8 \%$ depending on the geometric configuration of the road as well as the design of the vehicle [15]. In another similar study, Easa and Halim determined the minimum radius required for RHC design. The difference between this study and the previous study was the addition of intermediate tangents with lengths of 0,100 , 200 , and $300 \mathrm{~m}$ between two horizontal curves. It was concluded that an increase in the minimum radius of existing design guides (from 5\% to 27\%) is needed to compensate for the effects of inverse curvature and vertical alignment. As a result, longer intermediate tangents reduced "the increase in the minimum radius required" for the Truck's stability. Design requirements for the spiral length of RHCs are also presented [16].

Kordani et al. presented the following model to calculate the lateral friction coefficient in a horizontal curve combined with longitudinal slopes and in different conditions by simulating the movements of light and heavy vehicles such as E-class Sedan, SUV, and truck.

Lateral friction coefficient model for E-class Sedan is as shown in

$$
f=3.769-3.108 \ln \nu^{0.1}-0.003 g .
$$


Lateral friction coefficient model for SUV is as shown in

$$
f=0.663-0.12 \ln v+7.479 E-7 g^{3} .
$$

Lateral friction coefficient model for TRUCK heavy vehicle is as shown in

$$
f=0.827-0.155 \ln v-0.001 g,
$$

where $v$ is the vehicle speed $(\mathrm{km} / \mathrm{h})$, and $g$ is the slope in percentage. The results showed that the friction coefficient is affected by the vehicle's speed and the road's longitudinal slope.

In another study, the effect of a horizontal curve combined with longitudinal slopes was investigated by simulating the light and the heavy vehicles at different speed. The following results were obtained for the friction coefficient and the lateral acceleration [17]:

(A) A truck was exposed to more lateral aeccelerations on downgrades and less lateral accelerations on upgrades

(B) A higher lateral friction coefficient was created at the downgrades for all vehicles when turning on the curve

Echaveguren et al. have combined equations to obtain the equation of the point of intersection of the existing friction with the required friction by examining the friction studies while collecting an appropriate set of literature on the subject [18].

Varunjikar conducted a comprehensive study of horizontal curves combined with downgrades and performed a proper analysis of the behavior of vehicles while rotating on downgrades using various simulation software and models. According to the results, the superelevation rate does not significantly affect the amount of lateral friction required, especially at critical points (maximum friction required) [19].

In their research, Torbic et al. [20]; used a combination of vehicle dynamic simulation models, analysis, and data to evaluate the geometric design criterion for steep horizontal curves on steep slopes. Their research aimed to promote AASHTO's proposed modifications to develop conditions that could lead to concerns about steep horizontal curves on steep slopes. Friction data were collected from 8 sites, 21 of which measured frictions were recorded at each site, 9 of which were on the curve tangent, and the other 12 were in the horizontal curve range. The purpose of the friction test was to create the amount of available friction $\left(f_{\text {tire-pavement }}\right)$ for the wheels of vehicles and trucks that were suitable for modeling the expected behavior of vehicles on steep slopes and steep horizontal curves. The results showed that the maximum superelevation rate should not exceed $12 \%$ in the downgrades for a simple horizontal curve. If this value exceeds $12 \%$, a spiral curve is suggested to increase the safety margin between the curve's tangent and the horizontal curve. On upgrade of $4 \%$ or more, the maximum superelevation should be limited to $9 \%$ for small-radius curves with a design speed of $55 \mathrm{mph}$ and above to prevent wheel lift [20].
According to a review of prior studies, the primary themes of research are the horizontal and horizontal curves combined with the upgrade and downgrade slopes in distinct paths. However, the lack of a safety-base study that can simultaneously incorporate vehicle parameters into the proposed model encouraged the authors to use the dynamic vehicle modeling method and examine the safety of different vehicles passing through the RHC by considering the lateral friction coefficient as the main variable, given the use of RHC and RHC combined with the upgrade and downgrade slopes (especially on mountain roads).

\section{Research Methodology}

Point mass model method has been used to achieve road design formulas by AASHTO's Green book; however, due to various limitations such as not considering the longitudinal and lateral angles of the road surface and vehicle axis [21], lack of force distribution effect on different wheels, lack of road vertical patch specifications effect, and not considering the dimensions of vehicles [11], has questioned the application of this method. In this research, the safety of RHCs and the factors affecting them were investigated using the vehicle dynamic modeling method. For this purpose, the input data for the software is first considered. Then, the results were analyzed by performing simulation tests using Trucksim and Carsim simulation model. CarSim and TruckSim software are 3D simulation software designed and developed by Mechanical Simulation, based on more than thirty years of research in automotive dynamics.

Many major automakers have chosen this software as a convenient design tool and validated the actual results. Hence, this software does not suffer from a lack of validation. Finally, a multiple regression model based on the effective parameters was proposed.

\subsection{Modification Input Data}

3.1.1. Vehicles. Due to the wide range of vehicles on the roads and the fundamental differences between the geometric and mechanical characteristics of these vehicles, and in order to consider a wide range of existing vehicles, this study tried to estimate the impact of different vehicle parameters in the defined tests by selecting several types of vehicles. The vehicles considered in the simulation tests include two types of passenger cars (E-class Sedan, E-Class SUV), a type of Bus, and a type of Truck whose dimensional specifications are given in Table 1.

\subsubsection{Geometric Design of the Path and Pavement} Conditions. In order to design different path conditions and simulate different positions of the RHC relative to the longitudinal slopes (downgrade, upgrade, straight path), different modes of RHCs combined with longitudinal slopes have been used in this research (Table 2). Due to the longitudinal limitations in speed for the main routes, the design speeds of $80,100,120 \mathrm{~km} / \mathrm{h}$ have been used to design the road plan and profile. Also, seven modes were considered to 
TABLe 1: Specifications of the vehicle used in the research.

\begin{tabular}{|c|c|c|c|c|c|}
\hline \multirow{3}{*}{ Parameters } & \multicolumn{5}{|c|}{ Type of vehicles } \\
\hline & \multirow{2}{*}{ E-class sedan } & \multirow{2}{*}{ E-class SUV } & \multicolumn{2}{|c|}{ Conventional van loaded } & \multirow{2}{*}{ Bus } \\
\hline & & & Driver room part & Load part & \\
\hline Length $(\mathrm{mm})$ & 4250 & 4220 & - & 3000 & - \\
\hline Width (mm) & 1880 & 1875 & 2438 & 2000 & 2600 \\
\hline Height $(\mathrm{mm})$ & 1480 & 1800 & 3200 & 1000 & 2920 \\
\hline Distance between the wheels $(\mathrm{mm})$ & 3050 & 2950 & - & - & 4490 \\
\hline Height of the center of the wheel from the road surface $(\mathrm{mm})$ & 320 & 390 & - & - & - \\
\hline Height of the center of mass $(\mathrm{mm})$ & 530 & 720 & 1173 & 1800 & 1200 \\
\hline Weight $(\mathrm{kg})$ & 1650 & 1590 & 4457 & 6789 & 6360 \\
\hline
\end{tabular}

TABLE 2: Characteristics of reverse horizontal curves simulated in the road plan.

\begin{tabular}{|c|c|c|c|c|c|c|c|}
\hline & $V(\mathrm{~km} / \mathrm{h})$ & $R(\mathrm{~m})$ & $e(\%)$ & $M(\mathrm{~m})$ & $L_{\mathrm{c}}(\mathrm{m})$ & $L_{\mathrm{t}}(\mathrm{m})$ & $L_{\mathrm{r}}(\mathrm{m})$ \\
\hline & & & & 116 & & & \\
\hline & & & & 126 & & & \\
\hline \multirow[t]{5}{*}{1} & 80 & 230 & 8 & 146 & 361 & 14.5 & 58 \\
\hline & & & & 166 & & & \\
\hline & & & & 87 & & & \\
\hline & & & & 130 & & & \\
\hline & & & & 140 & & & \\
\hline \multirow[t]{5}{*}{2} & 100 & 395 & 8 & 160 & 620 & 16.25 & 65 \\
\hline & & & & 180 & & & \\
\hline & & & & 97.5 & & & \\
\hline & & & & 152 & & & \\
\hline & & & & 162 & & & \\
\hline \multirow[t]{3}{*}{3} & 120 & 667 & 8 & 182 & 1048 & 19 & 76 \\
\hline & & & & 202 & & & \\
\hline & & & & 114 & & & \\
\hline
\end{tabular}

express the position of the RHC combined with the longitudinal slopes. The route plan design includes right and left curves with a standard deflection angle of 90 degrees, two equal radii, and a straight path between two curves. According to the rules of AASHTO's Green book regulations, this route is designed with $80,100,120 \mathrm{~km} / \mathrm{h}$ design speeds.

In designing the path of RHCs for solving the problem of transverse slope at the point of intersection of two curves, a straight section is considered to create better conditions for exiting a transverse slope and entering another transverse slope to prevent sudden changes.

In this study, this direct distance was considered in five cases with the following conditions:

(A) With having a slope length of superelevation $\left(L_{\mathrm{r}}\right)$ and without opposite slope removal length $\left(L_{t}\right)$ and variable distance $(a=0)$

(B) Having slope length of superelevation $\left(L_{\mathrm{r}}\right)$ and having opposite slope removal length $\left(L_{t}\right)$ and variable distance $(a=0,10,30,50 \mathrm{~m})$

As a result, the total number of simulation tests required to perform this research is equal to 315 tests. Therefore, it can be said that there are several limitations, including the large number of tests, the limitation of driver behavior, and the time consuming of the tests.
After completing the simulation in order to obtain new equations, the output data of Trucksim and Carsim softwares were used for the inputs of the SPSS statistical analysis software to obtain the desired variable effect, such as the longitudinal slope. Finally, a comprehensive model for calculating friction was presented according to the available variables.

The design of the vertical routes includes the characteristics of the longitudinal slope of the upgrade and downgrade and the straight route, which is the entrance slopes. Six longitudinal slopes were used for the design, including $+2,+4,+6,-2,-4$, and $-6 \%$ as entrance slopes (upgrade and downgrade) and a zero longitudinal slope (straight route).

The maximum friction coefficient of the pavement surface is a value that indicates the reaction of the pavement surface to the car wheels. This coefficient is determined according to the type of pavement (concrete, asphalt, soil) or pavement surface conditions (dry, wet, and frozen). In this study, considering the asphalt pavement and dry condition, the friction coefficient of the pavement surface was considered to be 0.9 .

Driver behavior in this study was simulated by defining variables such as speed, brake, steering, gear, and vertical alignment. Given that a constant speed is assumed in the simulations, the brake and gear scenarios are assumed to be 
constant, with only speed and steering changes. In the simulations, the vehicle speed was considered equal to a constant speed of 80,100 , and $120 \mathrm{~km} / \mathrm{h}$. Due to the RHC at different speeds, the steering scenario is designed in such a way that the driver drives in a way that is always 1 meter away from the road axis.

\section{Simulations and Model Outputs}

Friction is a component that ensures the safety of the vehicle against slipping [22]. During vehicle movement, friction occurs due to the tire and pavement contact, which is created in two perpendicular directions:

(1) Longitudinal friction provides friction in the direction of vehicle movement and affects the increase or decrease of speed.

(2) Lateral friction creates the sliding and lateral friction required to move the car. The direction of this force is perpendicular to the direction of motion of the vehicle and allows the vehicle to change direction (Figure 2) (RERSO, 2007).

According to the simulation results, the forces on each vehicle's wheels are obtained under defined conditions. Using these results and Formula (4), the lateral friction coefficient can be obtained for each defined test.

$$
f_{\mathrm{y}}=\left|\frac{F_{\mathrm{y}}}{F_{\mathrm{z}}}\right| \text {, }
$$

where in: $f_{\mathrm{y}}=$ Lateral friction coefficient; $F_{\mathrm{y}}=$ Total lateral forces on the wheels of vehicles; $F_{z}=$ The total vertical forces on the wheels of the vehicles.

In order to calculate the lateral friction coefficient for different moving vehicles, diagrams of lateral and vertical forces on the wheels of different vehicles are studied in the occurrence of rutting and control mode. Figures 3(a) and 3 (b) shows an example of the lateral and vertical force on a Sedan vehicle. Also, the simulations of the four studied vehicles are shown in Figures 3(c)-3(f).

\section{Results and Discussion}

5.1. Analyzing the Effect of Speed Changes and Direct Distance Changes at Upgrade on the Lateral Friction Coefficient for the Design's Vehicles. By using simulation outputs, many results such as comparing the lateral friction coefficient of different vehicles, can be achieved in different conditions. Figure 4 shows the changes in the lateral friction coefficient by changing the straight distance $(D)$ on the upgrade for different speeds.

According to the results, the lateral friction coefficients of the Sedan increased (reduced safety) by increasing the longitudinal slope and at different straight distances (see Figure 4). However, the lateral friction coefficient of the SUV decreased (increased safety) under the mentioned conditions. The lateral friction coefficients of the Truck on the upgrade slopes were unchanged. This could be due to the Truck's heavyweight, which did not show much change on

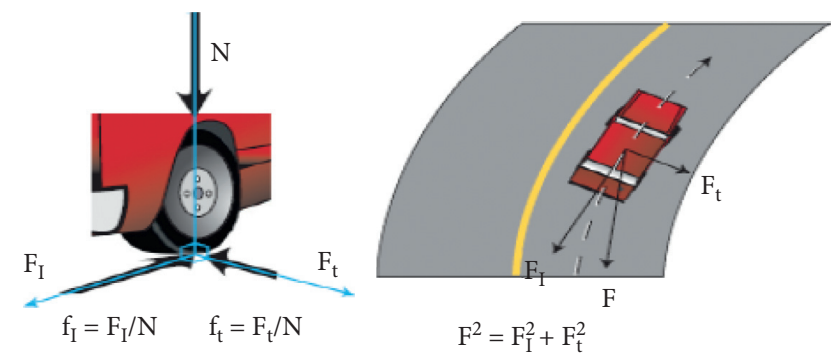

FIgURE 2: How the frictional force gets applied on the contact surface of rubber and pavement [23].

the upgrade. On the other hand, by increasing the speed from 80 to $120 \mathrm{~km} / \mathrm{h}$, the lateral friction coefficient of the Sedan and SUV decreased (increased safety). The reason for this result could be related to more driver control at higher speeds. However, the results showed that the lateral friction coefficient of the Truck decreased at the speed of $100 \mathrm{~km} / \mathrm{h}$ (increased safety) and increased at a speed of $120 \mathrm{~km} / \mathrm{h}$ (reduced safety). The results for the bus vehicle revealed that the lowest lateral friction coefficient was associated with a speed of $80 \mathrm{~km} / \mathrm{h}$. The lateral friction coefficient rose at all distances $D$ and slopes by increasing the speed from $80 \mathrm{~km} / \mathrm{h}$ to $100 \mathrm{~km} / \mathrm{h}$ and $120 \mathrm{~km} / \mathrm{h}$. According to Figure 4, as the slope of the upgrade increases, the probability of the Bus slipping increases since the lateral friction coefficient increases. However, in the upgrade scenario, the results indicated that the bus vehicle had a greater lateral friction coefficient than the Truck, indicating that this factor should be included in the designs.

AASHTO attributes the increase in lateral friction coefficient in the upgrades to the tractive force [7]. According to the results, it can be concluded that this happened for the Sedan and bus vehicles and that his result was not achieved for the other two types of vehicles. At upgrades and direct distance conditions, when $D=116 \mathrm{~m}$, speed is $80 \mathrm{~km} / \mathrm{h}$, and with a slope of $6 \%$, the maximum value of lateral friction coefficient for Sedan was equal to $f_{\mathrm{y}}=0.1542911$. Also, at a direct distance when $D=116 \mathrm{~m}$, a speed of $80 \mathrm{~km} / \mathrm{h}$, and a slope of $2 \%$, the maximum value of the lateral friction coefficient for an SUV is $f_{\mathrm{y}}=0.15590$. At all straight distances $(D)$, the speed of $120 \mathrm{~km} / \mathrm{h}$, and the slope of $6 \%$ resulted in the highest value of lateral friction coefficient for the TRUCK vehicle equal to $f_{\mathrm{y}}=0.06516$. Finally, the maximum value of lateral friction coefficient for a bus vehicle was fy $=0.08067$ for a straight distance of $D=202 \mathrm{~m}$, a speed of $120 \mathrm{~km} / \mathrm{h}$, and a slope of $6 \%$.

\subsection{Analyzing the Effect of Speed Changes and Direct Distance} Changes at a Direct Path on the Lateral Friction Coefficient for Design Vehicles. Figure 5 shows the changes in the lateral friction coefficient by changing the direct distance in the straight route for different speeds. Accordingly, the lateral friction coefficient of SUVs and Sedans decreases as speed increases (increased safety), and this is due to the increased radius of curve and increased straight length. While the lateral friction coefficient of the truck first decreased and 


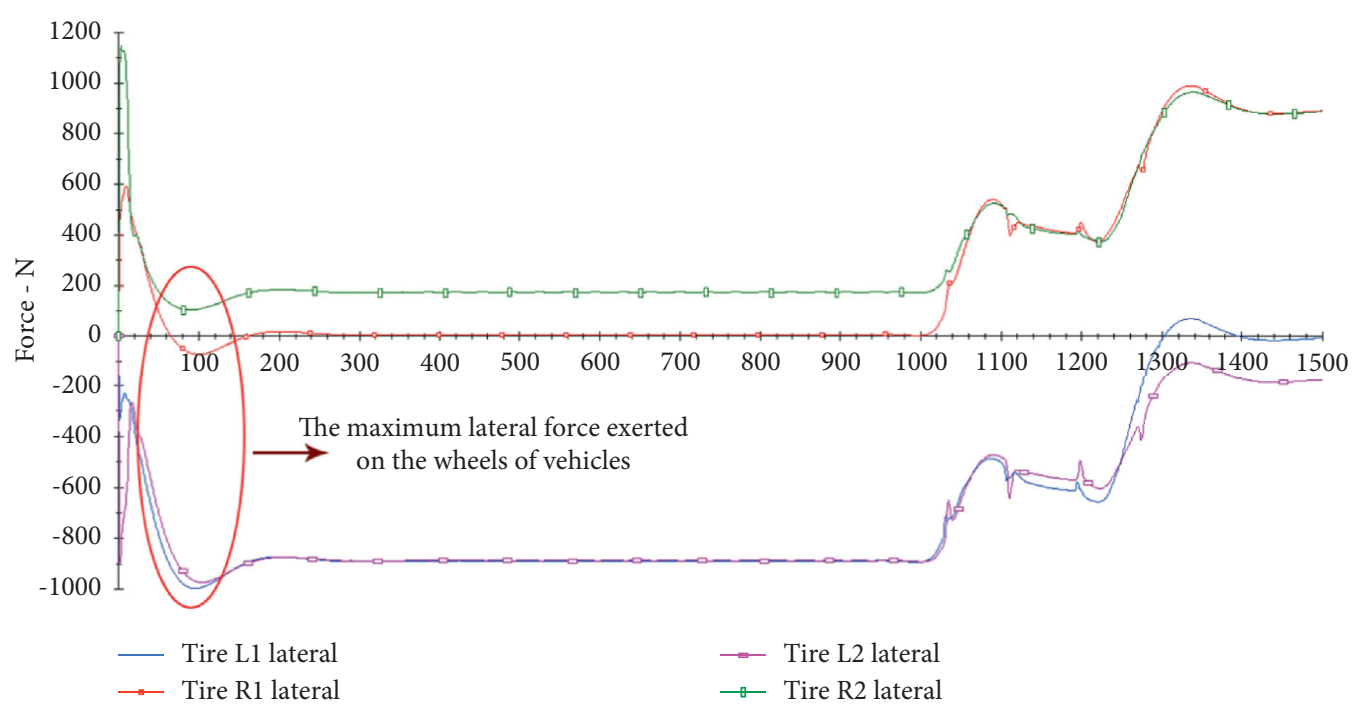

(a)

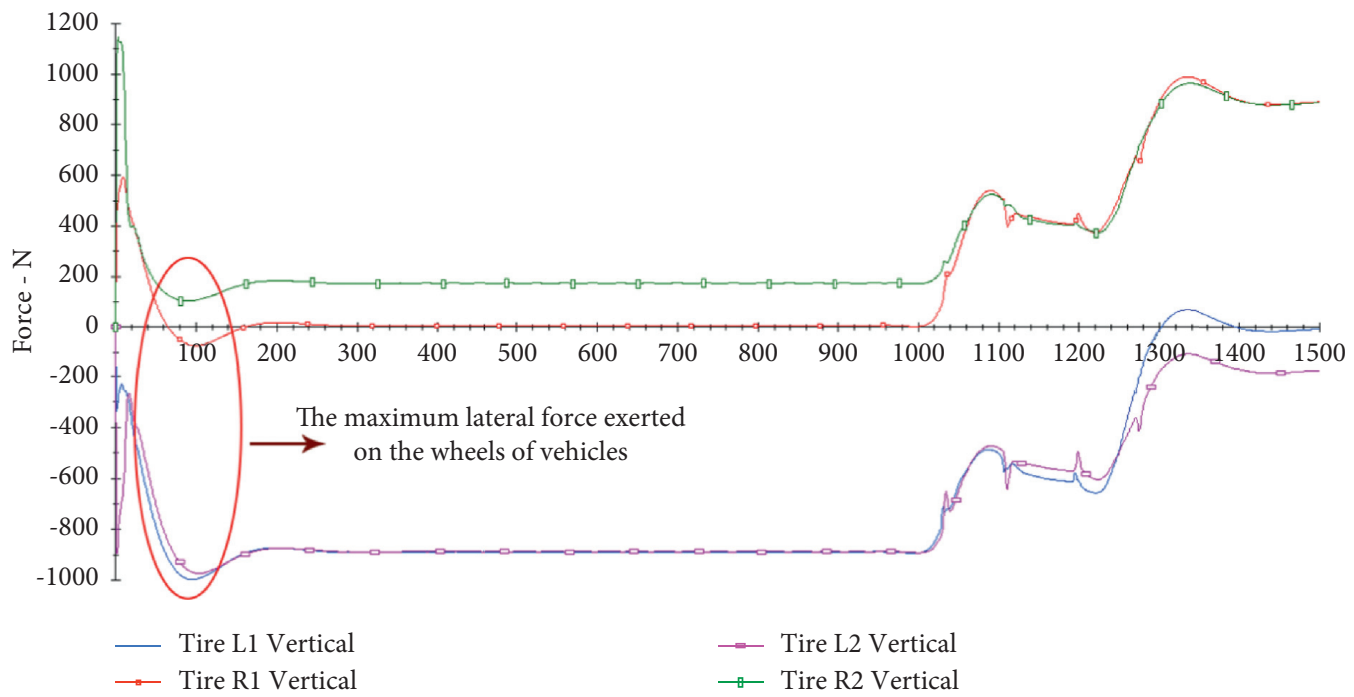

(b)

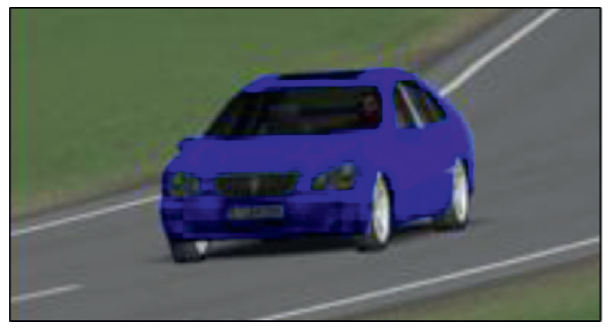

(c)

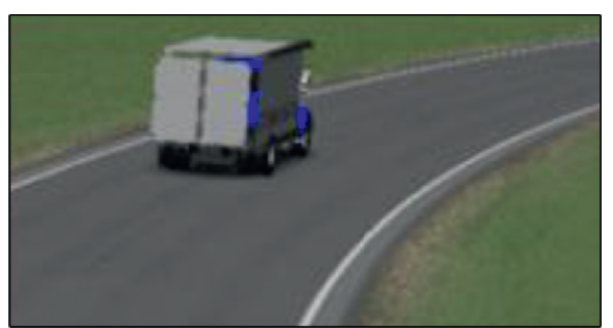

(e)

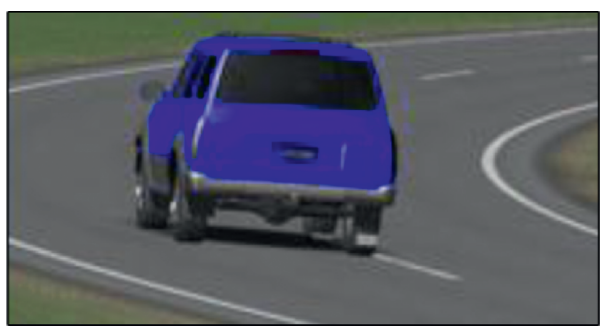

(d)

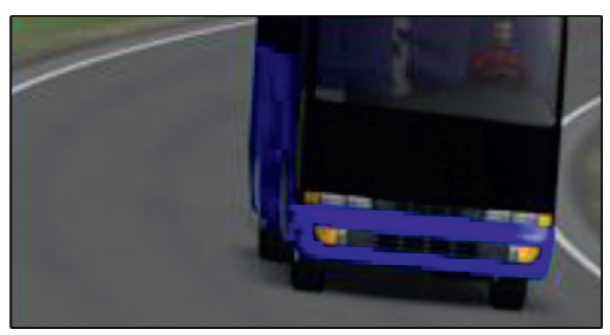

(f)

Figure 3: Simulation software output for the scenario with a speed of $120 \mathrm{~km} / \mathrm{h}$, a direct distance of $202 \mathrm{~m}$ and a slope of $5 \%$ : (a) Lateral force; (b) Vertical force; (c) Sedan vehicle simulation; (d) SUV vehicle simulation; (e) Truck vehicle simulation; (f) Bus vehicle simulation. 

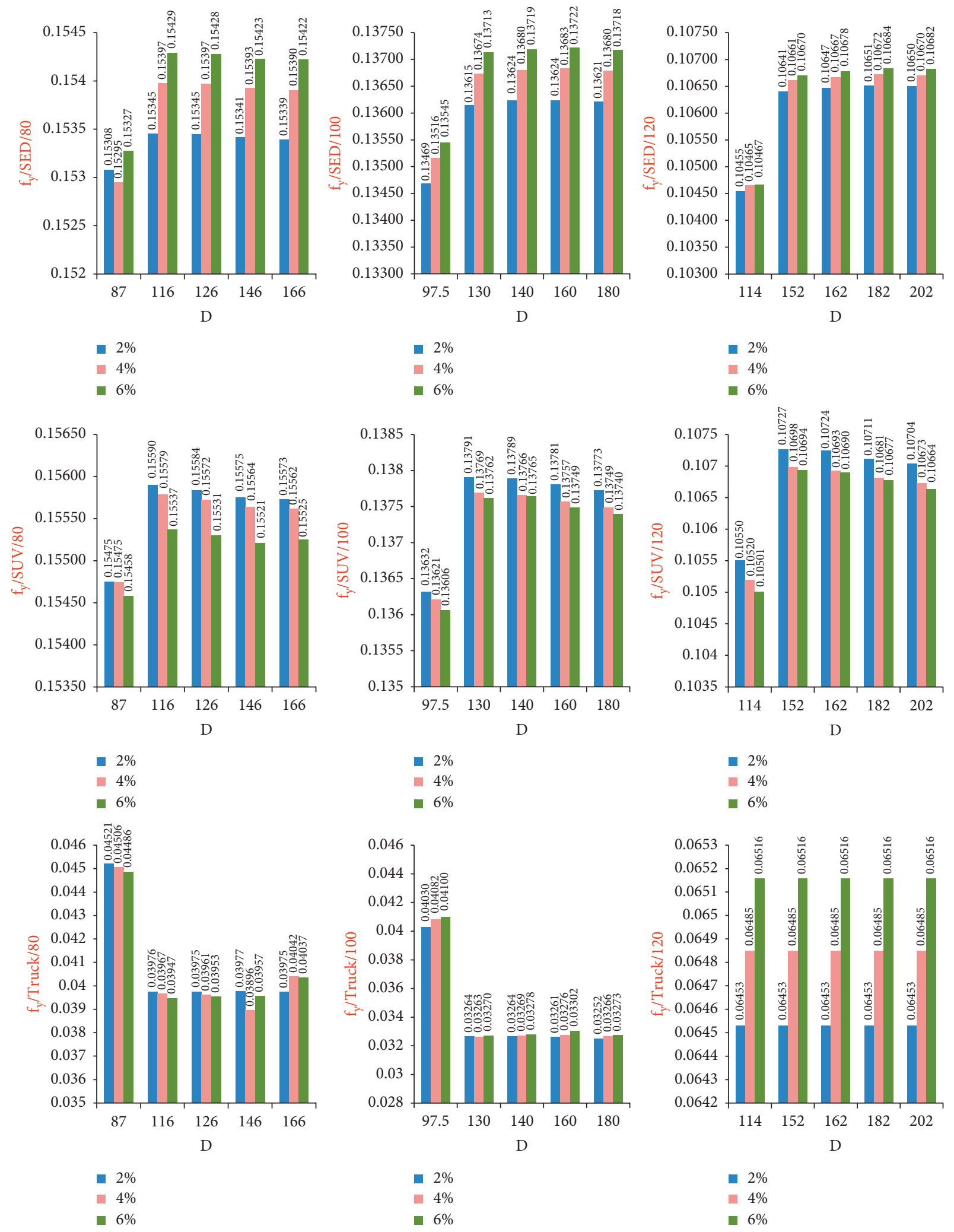

Figure 4: Continued. 

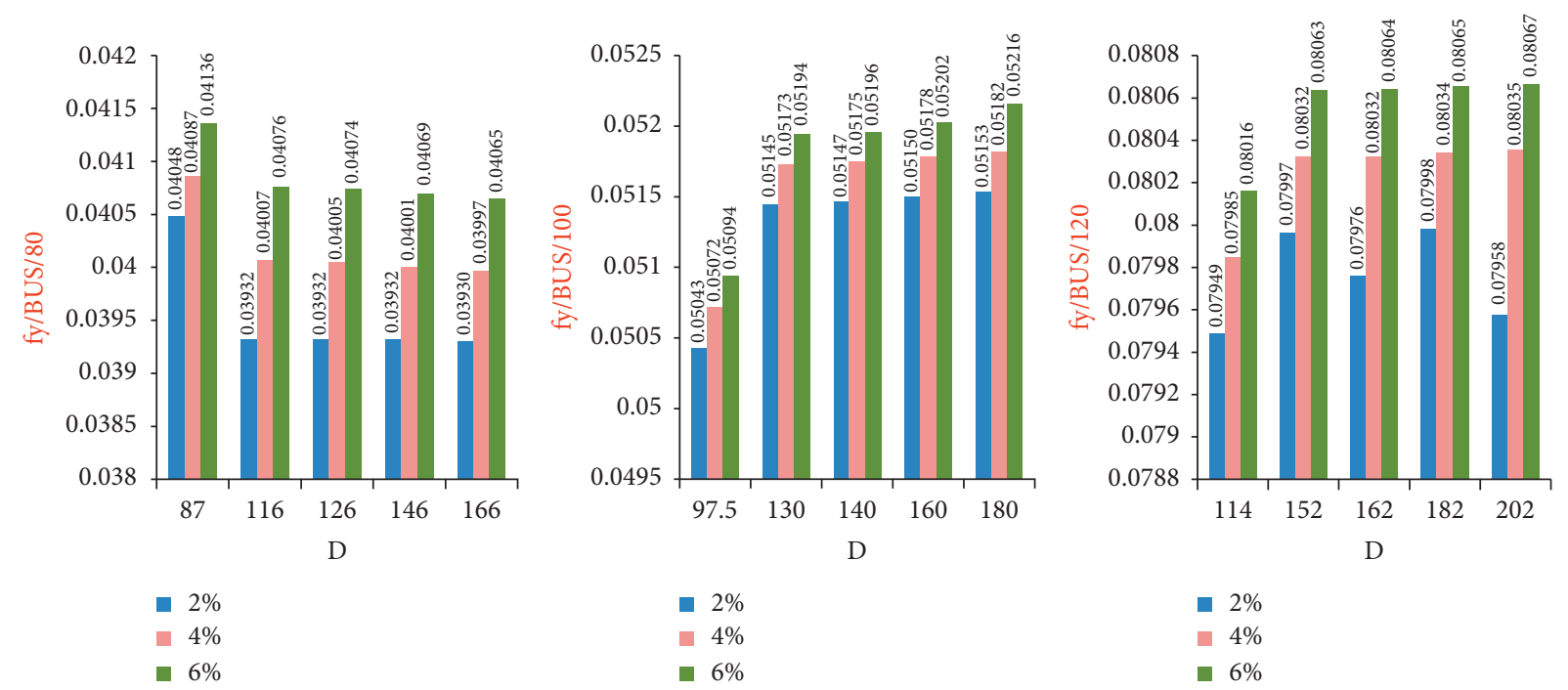

FIgURE 4: The lateral friction coefficient changes with direct distance change at upgrade and speeds of 80,100 , and 120 (km/h).
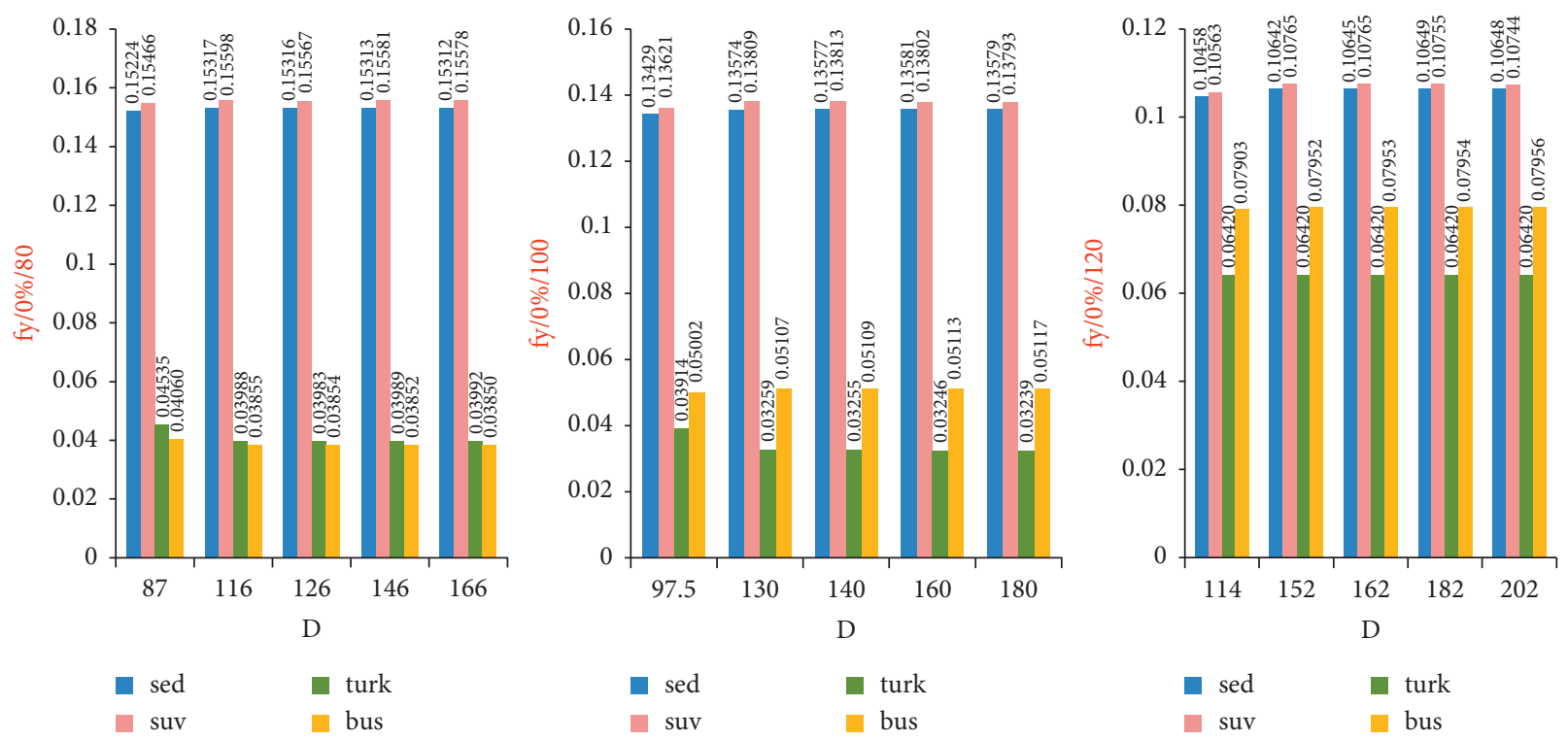

FIGURE 5: Changes in the lateral friction coefficient with direct distance change in straight scenario and speeds of 80,100 , and 120 (km/h).

then increased with increasing speed. According to Figure 5, the lateral friction coefficient of the SUV was slightly higher than that of the Sedan, which continued to increase slightly at different speeds. The bus vehicle's lateral friction coefficient increased from $80 \mathrm{~km} / \mathrm{h}$ to $120 \mathrm{~km} / \mathrm{h}$ once the vehicle's speed was increased. This behavior was equivalent to the instance involving the uphill climb scenario. By comparing the data of the Bus and the Truck, it can be inferred that the Bus had a higher potential for slippage at higher speeds than the Truck, which the designer should consider. In straight route scenario, at a speed of $80 \mathrm{~km} / \mathrm{h}$ and for a direct distance of $D=116 \mathrm{~m}$, the maximum value of lateral friction coefficient for Sedan was $f_{\mathrm{y}}=0.15317$. Also, at a speed of $80 \mathrm{~km} / \mathrm{h}$ and a direct distance of $D=116 \mathrm{~m}$, the maximum value of lateral friction coefficient for SUV was equal to $f_{\mathrm{y}}=0.15598$. At the speed of $120 \mathrm{~km} / \mathrm{h}$ and all direct distances, TRUCK's maximum lateral friction coefficient was equal to $f_{\mathrm{y}}=0.06420$. Finally, at a speed of $120 \mathrm{~km} / \mathrm{h}$ and direct distances $D=152 \mathrm{~m}$ and $162 \mathrm{~m}$, the maximum value of lateral friction coefficient for bus vehicle was equal to $f_{\mathrm{y}}=0.10765$.

5.3. Analyzing the Effect of Speed Changes and Direct Distance Changes at the Downgrade on the Lateral Friction Coefficient for Design's Vehicles. Figure 6 shows the changes in the lateral friction coefficient by changing the direct distance on the slope for different speeds. Based on the results, the 

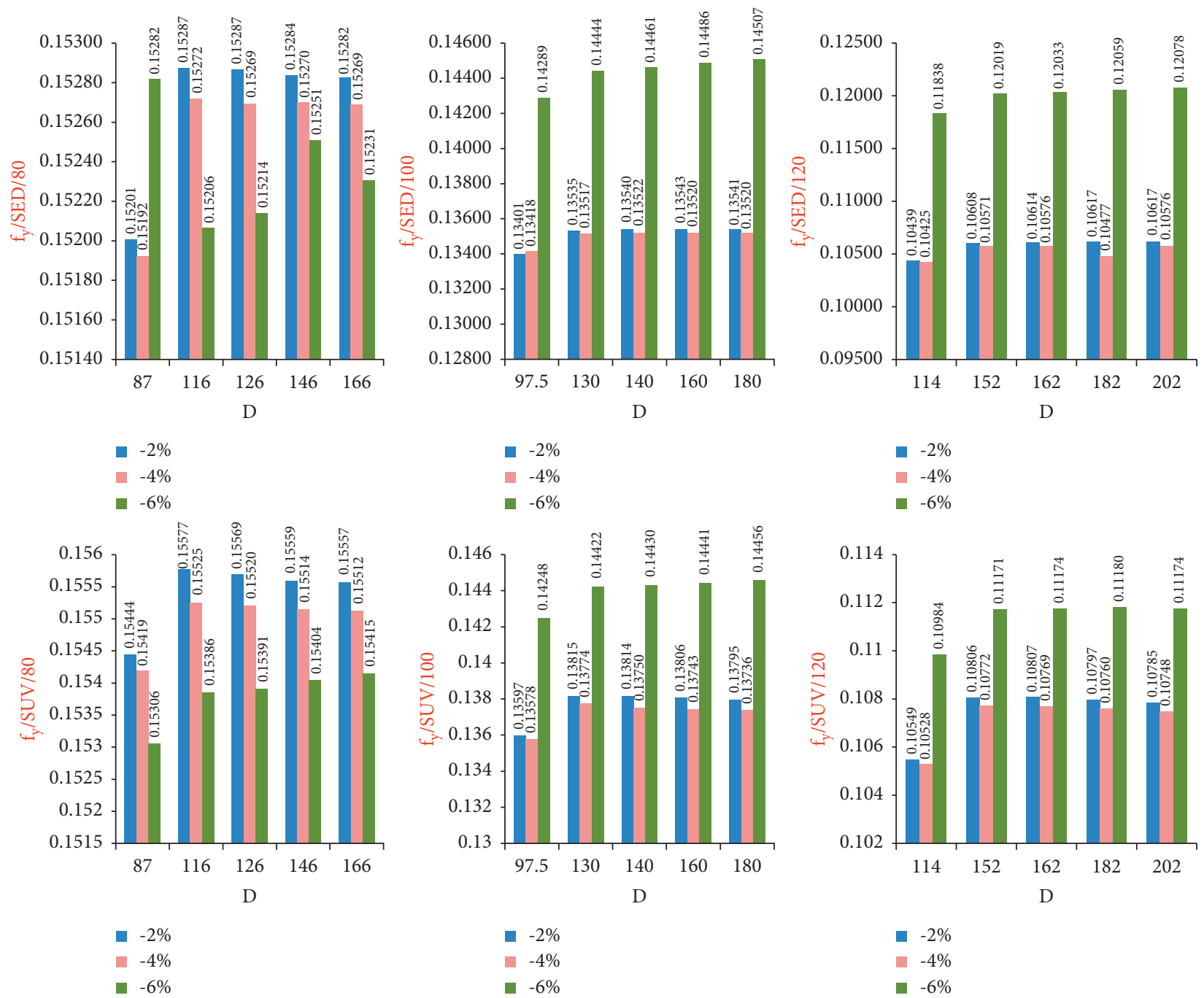

$-2 \%$
$-4 \%$
$-6 \%$

- $-2 \%$

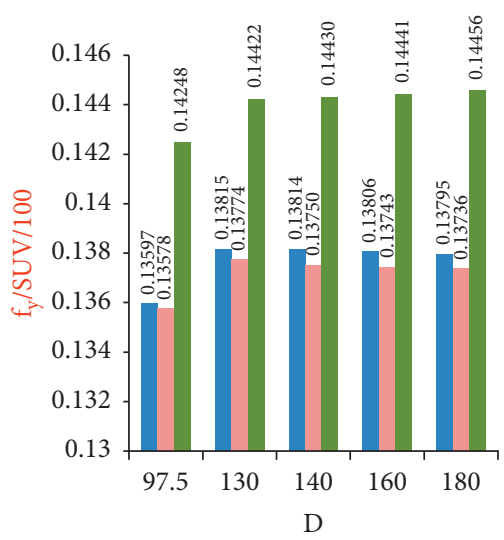

- $-6 \%$
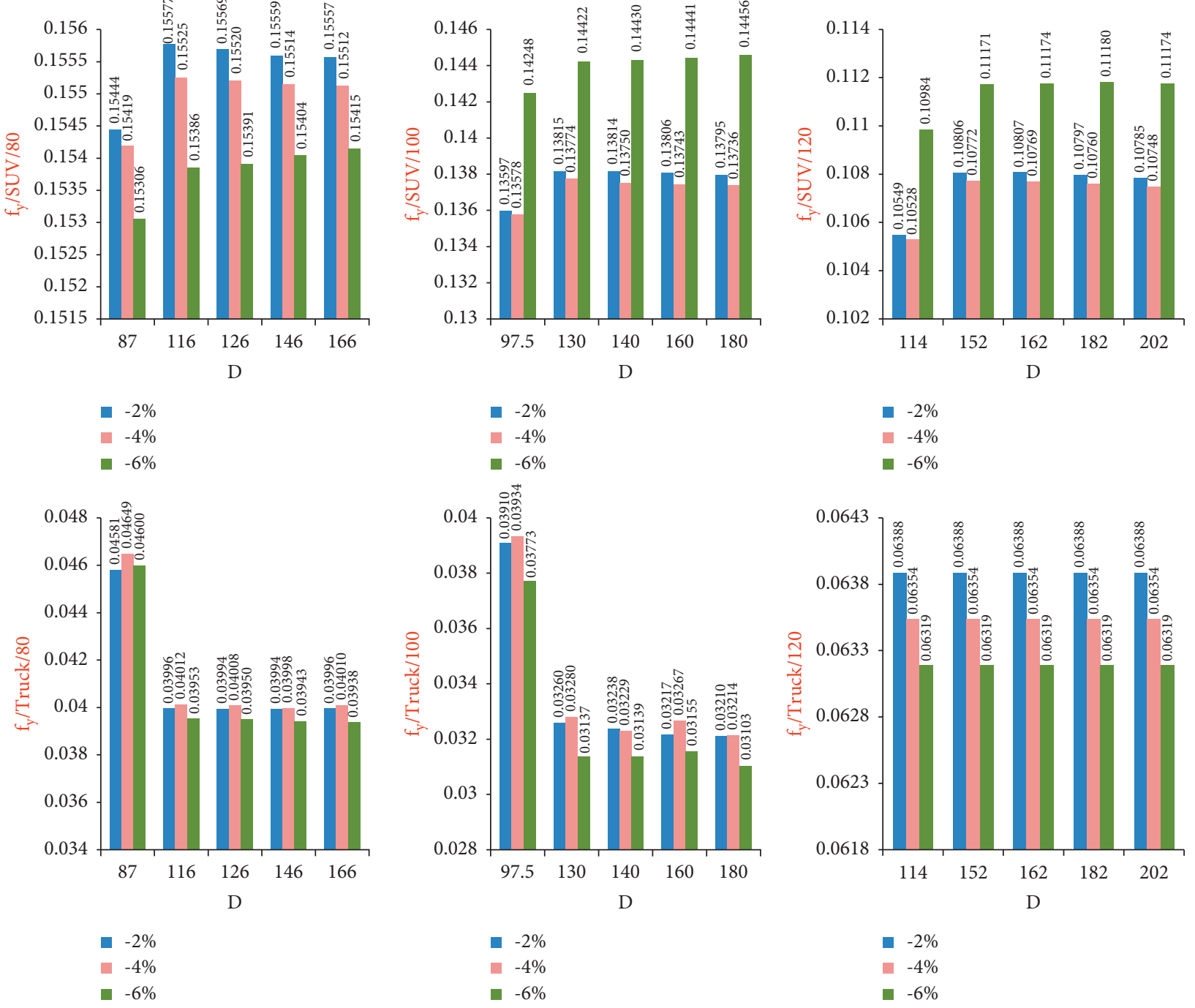

Figure 6: Continued. 

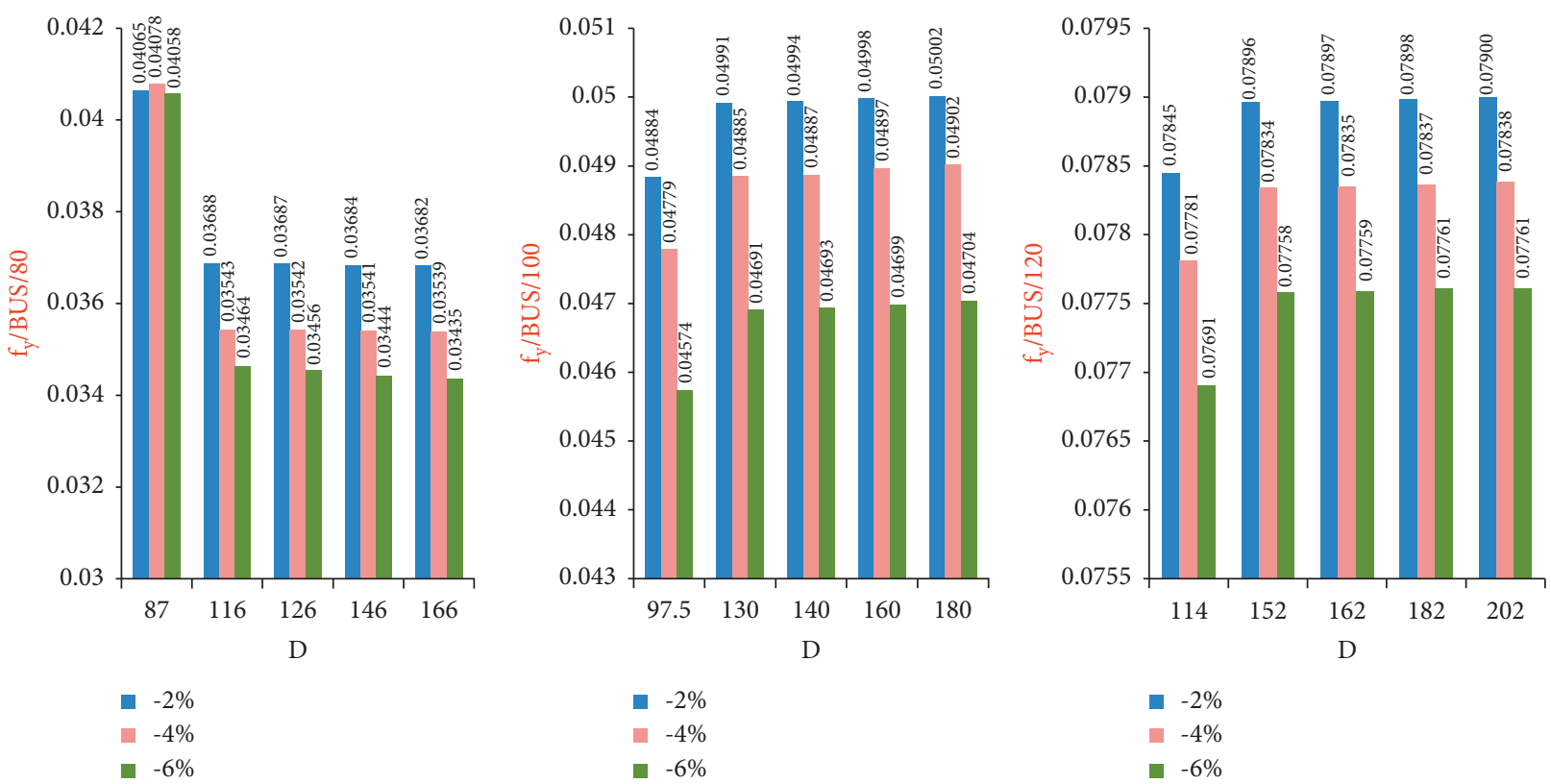

FIGURE 6: Lateral friction coefficient changes with direct distance changes in the downgrade scenario and speeds of 80, 100, and 120 (km/h).

process of changes in the lateral friction coefficient of the Sedan and SUV has had similar behavior in most of the results; thus, at a speed of $80 \mathrm{~km} / \mathrm{h}$ and with an increasing downgrade slope, the friction coefficient decreases. On the other hand, at speeds of 100 and $120 \mathrm{~km} / \mathrm{h}$ and by increasing the longitudinal slope's downgrade, the friction coefficient slightly decreased and increased significantly (reducing safety). For trucks, the lateral friction coefficient first decreases and then increases as the truck speed increases, while the lateral friction coefficient decreases (increasing safety) at each specific speed and with increasing downgrade slope. Increased speed resulted in a rise in the lateral friction coefficient for the bus vehicle, but the lateral friction coefficient decreased with increasing downgrade slope for each specified speed (increased safety). Due to the higher lateral friction coefficient of the Bus, it can be argued that the Bus has a higher probability of slipping than the Truck (this result was also obtained in the previous two scenarios). Therefore, this issue should be considered by the designer.

AASHTO [7] attributes the lateral friction coefficient increase in slopes to the braking force. It can be concluded that this occurred for Sedans and SUVs at speeds of 100 and $120 \mathrm{~km} / \mathrm{h}$. Based on the overall results, at a downgrade and at a straight distance $D=87 \mathrm{~m}$, a speed of $80 \mathrm{~km} / \mathrm{h}$, and slope of $-6 \%$, the maximum value of lateral friction coefficient for Sedan was $f_{\mathrm{y}}=0.15282$. At a direct distance of $D=116 \mathrm{~m}$, a speed of $80 \mathrm{~km} / \mathrm{h}$, and a slope of $-2 \%$ the maximum value of the lateral friction coefficient for the SUV was equal to $f_{\mathrm{y}}=0.155773$. At all straight distances, the speed of $120 \mathrm{~km} / \mathrm{h}$, and the slope of $-2 \%$ the maximum value of the lateral friction coefficient for the truck vehicle is $f_{\mathrm{y}}=0.063885$. Finally, at a speed of $120 \mathrm{~km} / \mathrm{h}$ and a direct distance of $D=202 \mathrm{~m}$, the maximum value of the lateral friction coefficient for the bus vehicle was fy $=0.07900$.

\section{Lateral Friction Coefficient Modeling}

After the simulation process and summarizing the outputs in the form of tables and graphs mentioned in the previous section, a set of multiple regression analyses was performed on the data by the SPSS software to provide new equations for improving the safety of geometric data design. These equations show changes in the lateral friction coefficient (dependent variable) based on the vehicle speed, longitudinal slope, vehicle type, and the direct distance between two curves as independent variables.

The purpose of the work is represented as

$y=\beta_{0}+\beta_{1} \cdot x_{i 1}+\beta_{2} \cdot x_{i 2}+\cdots+\beta_{k} \cdot x_{i k}+\varepsilon_{i}, \quad i=1, \ldots, n$,

where $y$ is the response variables, $x_{i k}$ are the explanatory variables, $\beta_{i}$ are the regression coefficients, $\varepsilon_{i}$ are the statistical model errors, and $n$ is the sample sizes.

6.1. Lateral Friction Coefficient Models of Sedan, SUV, Truck, and Bus. According to Tables 3 and 4, the obtained models for calculating the lateral friction coefficient for Sedan, SUV, Truck, and Bus corresponds to Equations (6)-(9).

$$
f_{\mathrm{y}-\mathrm{Sedan}}=0.245-0.001 \mathrm{~V}+\left(8.98 \times 10^{-6}\right) D\left(R^{2}=0.946\right)
$$

$$
f_{\mathrm{y}-\mathrm{SUV}}=0.244-0.001 \mathrm{~V}+\left(1.029 \times 10^{-5}\right) D\left(R^{2}=0.768\right),
$$


TABLE 3: ANOVA test results for vehicle's lateral friction coefficient.

\begin{tabular}{|c|c|c|c|c|c|c|}
\hline & Model & Sum of squares & Df & Mean square & $F$ & Sig \\
\hline \multirow{3}{*}{ Sedan } & Regression & 0.036 & 3 & 0.012 & 584.482 & $0.000^{\mathrm{b}}$ \\
\hline & Residual & 0.002 & 101 & 0.000 & & \\
\hline & Total & 0.038 & 104 & & & \\
\hline \multirow{3}{*}{ SUV } & Regression & 0.035 & 3 & 0.012 & 111.424 & $0.000^{\mathrm{b}}$ \\
\hline & Residual & 0.011 & 101 & 0.000 & & \\
\hline & Total & 0.046 & 104 & & & \\
\hline \multirow{3}{*}{ Truck } & Regression & 0.010 & 3 & 0.003 & 37.214 & $0.000^{\mathrm{b}}$ \\
\hline & Residual & 0.009 & 101 & 0.000 & & \\
\hline & Total & 0.018 & 104 & & & \\
\hline \multirow{3}{*}{ Bus } & Regression & 0.029 & 3 & 0.010 & 522.002 & $0.000^{\mathrm{b}}$ \\
\hline & Residual & 0.002 & 101 & 0.000 & & \\
\hline & Total & 0.031 & 104 & & & \\
\hline
\end{tabular}

${ }^{\mathrm{a}}$ Dependent variable: $F_{\mathrm{y}} \cdot{ }^{\mathrm{b}}$ Predictors: (constant), $D, G, V$.

TABLE 4: Model's coefficients for vehicle's lateral friction coefficient.

\begin{tabular}{|c|c|c|c|c|c|c|}
\hline & \multirow{2}{*}{ Model } & \multicolumn{2}{|c|}{ Unstandardized coefficients } & \multirow{2}{*}{$\begin{array}{c}\text { Standardized coefficients } \\
\text { Beta }\end{array}$} & \multirow{2}{*}{$t$} & \multirow{2}{*}{ Sig. } \\
\hline & & $B$ & Std. error & & & \\
\hline \multirow{4}{*}{ Sedan } & (Constant) & 0.245 & 0.003 & & 84.944 & 0.000 \\
\hline & V & -0.001 & 0.000 & -0.977 & -37.706 & 0.000 \\
\hline & $G$ & 0.000 & 0.000 & -0.062 & -2.672 & 0.009 \\
\hline & $D$ & $8.984 E-6$ & 0.000 & 0.015 & .575 & 0.566 \\
\hline \multirow{4}{*}{ SUV } & (Constant) & 0.244 & 0.007 & -0.881 & 37.213 & 0.000 \\
\hline & V & -0.001 & 0.000 & -0.058 & -16.478 & 0.000 \\
\hline & $G$ & 0.000 & 0.000 & 0.015 & -1.203 & 0.232 \\
\hline & $D$ & $1.029 E-5$ & 0.000 & & 0.290 & 0.773 \\
\hline \multirow{4}{*}{ Truck } & (Constant) & -0.010 & 0.006 & 0.750 & -1.736 & 0.086 \\
\hline & V & 0.001 & 0.000 & 0.026 & 9.805 & 0.000 \\
\hline & $G$ & $8.661 E-5$ & 0.000 & -0.064 & 0.384 & 0.702 \\
\hline & $D$ & $-2.673 E-5$ & 0.000 & & -0.836 & 0.405 \\
\hline \multirow{4}{*}{ Bus } & (Constant) & -0.046 & 0.003 & 0.961 & -16.758 & 0.000 \\
\hline & $V$ & 0.001 & 0.000 & 0.085 & 35.162 & 0.000 \\
\hline & $G$ & 0.037 & 0.011 & 0.010 & 3.463 & 0.001 \\
\hline & $D$ & $5.67 E-6$ & 0.000 & & 0.379 & 0.705 \\
\hline
\end{tabular}

${ }^{\mathrm{a}}$ Dependent variable: $f_{\mathrm{y}}$.

$$
\begin{aligned}
f_{\mathrm{y}-\text { Truck }}= & -0.01+0.001 V-\left(2.673 \times 10^{-5}\right) D \\
& +\left(8.661 \times 10^{-5}\right) G\left(R^{2}=0.525\right), \\
f_{\text {y-Bus }}= & -0.046+0.001 V-\left(2.673 \times 10^{-6}\right) D \\
& +0.037 G\left(R^{2}=0.939\right),
\end{aligned}
$$

$V$ : vehicle speed when entering the curve $(\mathrm{km} / \mathrm{h}) ; D$ : direct distance of inverted curve cycles (m); G: longitudinal slope (\%).

As can be seen from the models, speed and direct distance parameters are present in all models. Based on the results, the impact of these two parameters on the results of Sedans and SUVs has been the same. However, the opposite effect was obtained for truck and Bus. The effect of the $G$ parameter on the models was for the track and Bus. This can be attributed to the greater effect of the longitudinal slope of the track on the truck and bus.

6.2. Checking the Validation of the Model. Once the model is fitted to data, the validation of the model should be checked by examining the basic assumptions of a linear regression model. Model validation is probably the most important and sometimes the most challenging step in creating a model. It should be noted that $R$-squared is a criterion for "explained variation" and not a criterion for the accuracy of the fitted model [24]. The R-squared explains what percentage of the response variable variation can be explained by covariates included in the model. To evaluate the accuracy of the model, we must use diagnostic techniques as in Section 6.2.

6.2.1. The Effect of Explanatory Variables on the Model. For Sedans, SUVs and bus, considering the significance of each variable, it was concluded that the variables of speed and longitudinal slope of the RHC have a relatively good effect on the model. However, the direct distance variable has a negligible effect on the model concerning 0.566 and 0.773. For the Truck, and according to the significance of each variable, it was concluded that the variable of speed have a relatively good effect on the model. However, the longitudinal slope variable has a negligible effect on the model with a value of 0.702 . Finally, for the bus model, and 

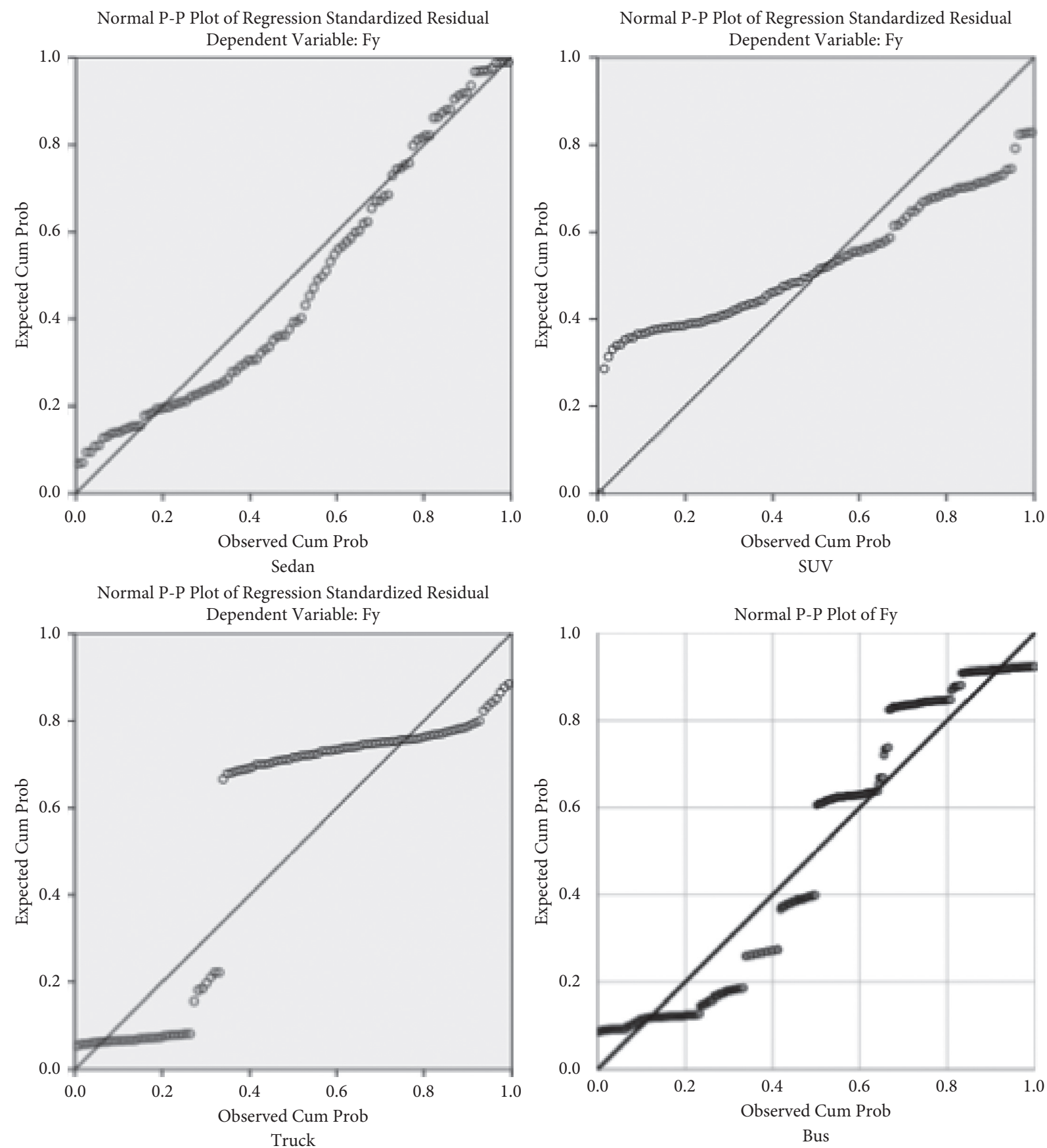

FiguRE 7: Correlation of lateral friction coefficient model for different scenarios.

according to the significance, it was concluded that the variables of speed and slope have a relatively good effect on the model. However, the variable direct distance has a slight effect on the model with a value of 0.705 .

6.2.2. Normality of the Residuals. The normality of the residues can be visually checked with a histogram or a $\mathrm{q}-\mathrm{q}$ chart. Also, the Kolmogorov-Smirnov test can be used to determine the assumption of normality at a certain level of importance. The residual histogram and $\mathrm{q}-\mathrm{q}$ for the model shown in Figure 7 show the normality of the residual. Also, the result of the Kolmogorov-Smirnov test confirms normality at a significance level of 0.05 (0.00452 for Sedan, 0.01028 for SUV, 0.00924 for Truck, and 0.02720 for bus model).

6.2.3. Multicollinearity. A multicollinearity occurs when the explanatory variables are not statistically independent. This causes difficulties in estimation of the regression coefficients [24]. One way to determine this parameter is the Variance Inflation Factor (VIF). The VIF criterion defined as VIF $=1$ / $\mathrm{T}$, where $T=1-R^{2}$ shows the tolerance measure. This can be a 
problem when the VIF value is greater than 100 . Considering the value of $R^{2}$, we can say that the value of VIF for all four models was $18.51,4.18,2.10$, and 16.40 , respectively, which indicates no problem.

\section{Conclusions}

This study investigated the safety of the RHCs of highways using the lateral friction coefficient of different vehicles using the dynamic vehicle modeling method. Due to the exorbitant costs of field study in this research, the results of this study can be valuable for engineers and designers. The results showed that the different parameters involved in the research showed different effects on the modeling results. However, based on the results, the validation of the obtained models showed that these models could be used as an experimental equation to estimate the friction coefficient of the asphalt pavement in RHCs of highways. According to the results of this study, the vertical alignment of the route, when combined with the RHC, creates more severe safety conditions for vehicles. Some of the most important results are briefly mentioned in this section.

(i) According to the studies performed by the vehicle simulation model, the maximum values of lateral friction coefficient are for the SUV vehicle, the Sedan, the bus, and finally the truck, respectively. The highest lateral friction coefficient of the Sedan vehicle is at upgrade and downgrade at $80 \mathrm{~km} / \mathrm{h}$ in a direct distance between 116 and 87 with a slope of $+6 \%$ and $-6 \%$. Also, the maximum lateral friction coefficient of the SUV vehicle is at the upgrade and downgrade at $80 \mathrm{~km} / \mathrm{h}$ with a direct distance of $116 \mathrm{~m}$ and a slope of $+2 \%,-2 \%$. The maximum lateral friction coefficient of the truck and bus vehicles is at the upgrade and downgrade at a speed of $120 \mathrm{~km} / \mathrm{h}$, at all direct distances with a slope of $+6 \%$ and $-2 \%$. This hypothesis confirms the research and states that critical situations are created if $\mathrm{RCH}$ are combined with longitudinal slopes (downgrade and upgrade).

(ii) The higher the design's speed and the shorter the direct distance, the lower the lateral friction coefficient for the Sedan and SUV; hence, the vehicle's safety is excellent. Reduced speed, increased direct distance, and reduced slope led to increased safety for the truck and bus.

(iii) Due to the higher lateral friction coefficient of the Bus, it can be argued that the Bus has a higher probability of slipping than the Truck (this result was also obtained in the previous two scenarios). Therefore, this issue should be considered by the designer.

(iv) By comparing different vehicles in the simulation results, it can be concluded that the truck vehicle has a lower lateral friction coefficient than the Bus and the two passenger vehicles, Sedan and SUV, at all speeds and slopes. Thus, it has a lower potential for slipping in all conditions. This is because the truck vehicle applies more vertical force to its wheels due to being heavier than the other two vehicles, which reduces the lateral friction coefficient created between the pavement and the wheels of this vehicle.

For future studies, the authors propose to study different types of vehicles at speeds of less than $80 \mathrm{~km} / \mathrm{h}$ and more than $120 \mathrm{~km} / \mathrm{h}$. It is also suggested that the effect of some parameters such as the effect of braking scenario on the lateral friction coefficient of vehicles be investigated.

\section{Data Availability}

No data were used to support this study.

\section{Conflicts of Interest}

The authors declare that there are no conflicts of interest regarding the publication of this paper.

\section{References}

[1] National Highway Traffic Safety Administration, "National motor vehicle crash causation survey: report to congress," National Highway Traffic Safety Administration Technical Report DOT HS, vol. 59, 2008.

[2] R. Elvik, "The more (sharp) curves, the lower the risk," Accident Analysis \& Prevention, vol. 133, Article ID 105322, 2019.

[3] D. J. Findley, J. E. Hummer, W. Rasdorf, C. V. Zegeer, and T. J. Fowler, "Modeling the impact of spatial relationships on horizontal curve safety," Accident Analysis \& Prevention, vol. 45, pp. 296-304, 2012.

[4] T. Saleem and B. Persaud, "Another look at the safety effects of horizontal curvature on rural two-lane highways," Accident Analysis \& Prevention, vol. 106, pp. 149-159, 2017.

[5] G. Khan, A. R. Bill, M. V. Chitturi, and D. A. Noyce, "Safety evaluation of horizontal curves on rural undivided roads," Transportation Research Record: Journal of the Transportation Research Board, vol. 2386, no. 1, pp. 147-157, 2013.

[6] X. Wang and X. Wang, "Speed change behavior on combined horizontal and vertical curves: driving simulator-based analysis," Accident Analysis \& Prevention, vol. 119, pp. 215-224, 2018.

[7] Aashto, A Policy on Geometric Design of Highways and Streets, Seventh Edition, AASHTO, Washington, D.C., USA, 2018.

[8] J. A. Bonneson, Superelevation Distribution Methods and Transition Designs, Transportation Research Board, Washington D.C., USA, 2000.

[9] K. Musey and S. Park, "Pavement skid number and horizontal curve safety," Procedia Engineering, vol. 145, pp. 828-835, 2016.

[10] M. Moradi, A. Abdi Kordani, and M. Zarei, "New geometric design approach to reduce vehicle's speed in accident-prone downgrade highways using dynamic vehicle modeling," Journal of Transportation Engineering, Part A: Systems, vol. 147, no. 1, Article ID 04020149, 2021.

[11] Y. Hassan, S. M. Easa, and A. O. Abd El Halim, "State-of-theart of three-dimensional highway geometric design," Canadian Journal of Civil Engineering, vol. 25, no. 3, pp. 500-511, 1998. 
[12] T. Nakatsuji, T. Kaku, T. Fujiwara, T. Hagiwara, and Y. Onodera, Dynamic Behavior of a Vehicle On A Rutted Road. In Surface Characteristics Of Roadways: International Research And Technologies, ASTM International, West Conshohocken, PA, USA, 1990.

[13] R. W. Eck and L. J. French, "Effective superelevation for large trucks on sharp curves and steep grades," West Virginia Department of Transportation Research Projectp, Morgantown, WV, USA, (No. Research Project 153), 2002.

[14] J. R. Morrall and R. J. Talarico, "Side friction demanded and margins of safety on horizontal curves," Transportation Research Record, vol. 1435, pp. 145-152, 1994.

[15] E. Dabbour, S. M. Easa, and A. O. A. E. Halim, "Radius requirements for reverse horizontal curves on three-dimensional alignments," Journal of Transportation Engineering, vol. 130, no. 5, pp. 610-620, 2004.

[16] S. M. Easa and A. A. E. Halim, "Radius requirements for trucks on three-dimensional reverse horizontal curves with intermediate tangents," Transportation Research Record: Journal of the Transportation Research Board, vol. 1961, no. 1, pp. 83-93, 2006.

[17] A. M. Molan and A. A. Kordani, "Multi-body simulation modeling of vehicle skidding and roll over for horizontal curves on longitudinal grades," in Proceedings of the Transportation Research Board 93rd Annual Meeting, Washington D.C., WA, USA, January 2014.

[18] T. Echaveguren, M. Bustos, and H. D. Solminihac, "A method to evaluate side friction InHorizontal curves, using supplydemand concepts," in Proceedings of the 6th International Conference on Managing Pavements, Brisbane Queensland, Australia, October 2004.

[19] T. Varunjikar, "Design of horizontal curves with downgrade using low-order vehicle dynamics models. The Pennsylvania state university. The graduate school," Department of $\mathrm{Me}$ chanical Engineering, https://etda.libraries.psu.edu/files/final_ submissions/6250, 2011.

[20] D. J. Torbic, E. T. Donnell, S. N. Brennan, A. Brown, M. K. O'Laughlin, and K. M. Bauer, "Superelevation design for sharp horizontal curves on steep grades," Transportation Research Record: Journal of the Transportation Research Board, vol. 2436, no. 1, pp. 81-91, 2014.

[21] A. Brown and S. Brennan, "On the required complexity of vehicle dynamic models for use in simulation-based highway design," Journal of Safety Research, vol. 49, pp. 105-112, 2014.

[22] S. Mavromatis and B. Psarianos, "Analytical model to determine the influence of horizontal alignment of two-axle heavy vehicles on upgrades," Journal of Transportation Engineering, vol. 129, no. 6, pp. 583-589, 2003.

[23] European Road Safety Observatory, "Road," 2007, http:// www.erso.eu.

[24] A. A. Kordani, S. Javadi, and A. Fallah, "The effect of shoulder on safety of highways in horizontal curves: with focus on roll angle," KSCE Journal of Civil Engineering, vol. 22, no. 8, pp. 3153-3161, 2018.

[25] A. A. Kordani, A. M. Molan, and S. Monajjem, "New formulas of side friction factor based on three-dimensional model in horizontal curves for various vehicles," in Proceedings of the T\&DI Congress 2014: Planes, Trains, and Automobiles, pp. 592-601, Orlando, FL, USA, May 2014. 